\title{
Letter from Moscow: complementary medicine under glasnost
}

\author{
G E Falkowski
}

The inability of the Soviet medical services to cope adequately with the health needs of the general population is widely recognised and discussed at various levels. There are many reasons for this, both traditional and non-traditional, but they are to a large extent based on the concept that your life should be spared for future generations. One of the most interesting and obscure phenomena under glasnost is the appearance of a rather large number of people claiming to possess various kinds of extrasensory, psychotherapeutic, and clairvoyant healing abilities. These people are given wide publicity in the mass media and have recently even appeared on television.

\section{Miraculous recovery}

One of them gave a séance on the first channel of Soviet television at the end of October. His name is A M Kashpirovsky, and the whole country is talking about him. A somewhat tough looking man of about 40 with penetrating eyes, crew cut dark hair, masculine features, and the neck of a professional wrestler, he appeared on television seated before an audience of about 800 people, mostly middle aged women. His expression was grave with no trace of a smile " There is too much sorrow in the world to smile," he observed later). He began the séance by addressing 10 Afghan war veterans, as the young men who saw active service in the war in Afghanistan are called here, and donated 5000 roubles in cash to them (the equivalent of about $\$ 5000)$. Afterwards he presented one crippled Afghan war veteran with a Japanese wheelchair, a gift from the manager of a Kuzbass coal mine.

Then members of the audience-people from all parts of the Soviet Union, as it turned out during the course of the séance-came to the microphone to speak of their well nigh miraculous recoveries from long term ailments. The list of these was quite amazing: disappearance of all kinds of scars, external and internal, and of post traumatic paraplegias and hemiplegias, ovarian cysts, cancer metastases, varicose veins, and thrombophlebitis, to mention but a few. One woman said that she had lost $38 \mathrm{~kg}$ in weight, another that she had become pregnant after one of Mr Kashpirovsky's television séances. Then there was a young West German actress who had suddenly and inexplicably gone completely bald. She was invited to the platform, where with her permission Mr Kashpirovsky stroked her thick, short hair with obvious satisfaction, while her father told the audience how he had taken her all over the world in search of a cure for her baldness without success until he had gone to Kiev to consult Kashpirovsky.

Mr Kashpirovsky, who calls himself a psychoCardiovascular Surgery Leninski prospect 8, Moscow

G E Falkowski, MD, professor of paediatric cardiovascular surgery therapist, emphasised repeatedly that he was in no way opposed to official medicine. On the contrary, he was anxious to cooperate. "We must work together," he said, addressing a woman doctor who had reported that two of her patients had been completely cured

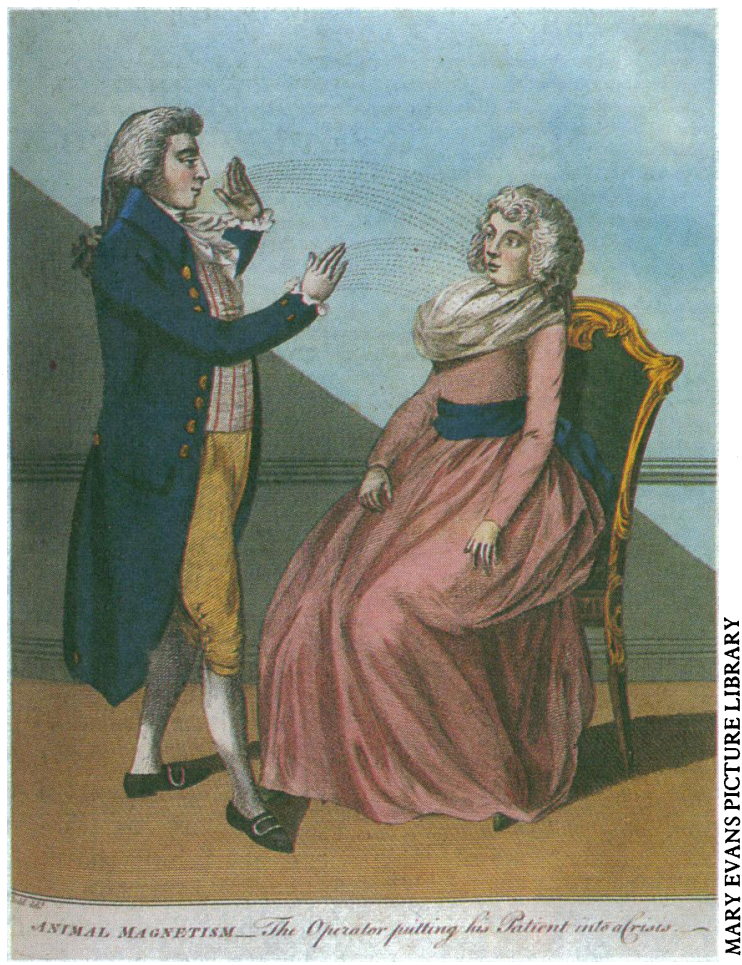

Mesmerist at work. Television could have increased his sphere of influence

after two television séances with Kashpirovsky. Incidentally, he insists on the documentation of every case referred to him. He believes in the powerful and untapped capacity of the subconsciousness. "I try to penetrate the subconsciousness direct," he said.

He began the séance after reading aloud many letters and telegrams from all corners of the Soviet Union, mostly reporting remarkable progress in recuperation from long term illnesses and thanking him warmly for his help, though there was one letter telling him to stop talking nonsense. He said that treatment by television, which he repeatedly declared was just as good as direct contact, is most effective in curing osteopathies, high blood pressure, breast tumours, erosions, ulcers, scars, and varicose veins. That did not mean, he said, that ailments he had not named specifically would not respond to his treatment. Then, looking straight at the screen he began to speak. In a quiet, well modulated voice he said that he had come to bring ease and comfort to us, to assure us that all would be well with us, our families, and the country, that his message was one of goodness and kindness. "I relieve you of all strains and stresses. Forget the stresses. All my powers are concentrated on healing, curing, giving relief from strains and stresses, relief from pain; I call for normal behaviour. Be calm and relaxed. Give full rein to your thoughts; float along with your thoughts. Stop weep- 
ing, you have wept enough; dry your tears. I adjure to you-do not kill, do not use bad language. I adjure smokers and alcoholics and drug addicts to stop destroying themselves. I am not a mystic. My mission is to make you believe in my power. It is phenomenal, but it exists and it is unique. Children, heed your parents. Do not torment cats and dogs, they also feel pain when hurt."

The camera showed the audience. Some people were swaying sleepily in their seats; a few men were waving their arms as if doing sedentary exercises. Most people sat with their eyes closed, although he said it did not matter whether they were open or closed. "Don't worry about your involuntary movements. That is how it should be. It will pass as soon as I stop." He ended his séance by counting to 33 .

His major theses were good. His appeals and messages were human and natural. He struck me as a well intentioned person, a philanthropist keen to use his unusual powers. After the séance I felt sleepy, but I usually do at $11 \mathrm{pm}$. My wife claimed, however, that her legs and arms felt a little heavier as he talked, and my mother in law aged 85 said the next morning that she had a good night's sleep, something which had not happened for a long time. In any case, the séance was a welcome relief from the war or revolutionary films that have for years been the usual entertainment on television on a Sunday night.

Meanwhile I am waiting hopefully for the long term effects of $\mathrm{Mr}$ Kashpirovsky's magnetic treatment because I have now been quite bald for 30 years.

What does it all mean? Is it a manifestation of the preoccupation with the mystic, the inexplicable that is a part of the Russian character (remember Gogol, Dostoyevsky, Rasputin), or a truly psychotherapeutic influence projected by Mr Kashpirovsky?

\section{Following in the steps of Mesmer et al}

It all seemed vaguely familiar. Somewhere, sometime I had read or heard about such phenomena. And then I remembered: it had all been described and analysed by Professor Sergei Yudin in a chapter in his selected works entitled "Profiles of the Past in the Development of Surgical Anaesthesia." The manuscript was written during 1946-7, just before his imprisonment and exile to Siberia in 1948, and was not published until 1960.

Professor Yudin (1891-1954), a brilliant surgeon with a worldwide reputation, was a man of many parts. Founder of the Sklifosovsky Institute of Emergency Medicine in Moscow, he was an outstanding figure in Soviet surgery, a pioneer of many gastric and oesophagael operations, and made creative contributions to every subject he was concerned with. In the analysis of the history of anaesthesia he devoted considerable space to the story of Dr Franz Anton Mesmer and animal magnetism. Dr Mesmer, who lived in the late eighteenth century, clearly possessed the same powers as Mr Kashpirovsky and the other practitioners of "alternative medicine" of today. He, too, rapidly won great renown throughout Europe, and the word mesmerism was widely used. I am sure that if television had been invented in his day and he had had as much time on the screen as Mr Kashpirovsky the effect would have been identical.

\section{Beware the Ides of October}

\section{R H Ratnasuriya}

Six weeks at home in Sri Lanka was just what I needed to recharge my batteries after starting a new job where I was the only consultant. As I had just reached a major watershed in my life my wife and I thought it might be an interesting exercise to visit an astrologer when we were home.

\section{... the full force of his wrath had been diluted because I was not living in my birthplace.}

After about three weeks trouble broke out in various parts of the country and a 24 hour curfew was declared for three days. This provided a respite from all the rushing around meeting friends and relatives. After three days a night curfew was enforced and during one evening's conversation someone mentioned an astrologer who was supposed to be very good. Apparently government ministers and other high officials visited him.

Curiosity compelled us to visit him and one afternoon we found ourselves being shown into his sitting room. His house was about 200 yards away from a trickle which had once been a mighty river but had been dammed about six $\mathrm{km}$ upstream. The sound of clothes being beaten and washed against the rocks was the only noise that joined the occasional chatter of birds in the searing afternoon sun.

The introduction made no mention of profession or background. We were soon shown into the astrologer's study, which was a converted garage. On one wall was a magiboard on which there were remnants of someone else's charts. We were told that we were lucky as he had no one to see that afternoon. As we sat down a well known businessman turned up from Colombo and was told to go away and come back another day. The astrologer's waiting list was something like two to three weeks. Was it fate that had cleared a slot for us?

The time and date of birth soon provided the essential basic information for the construction of my chart. First names are usually given according to auspicious sound and he asked me to confirm whether my first name started with the sounds that he picked out from his calculations. Volumes of reference books, a pocket calculator, and a slide rule helped him in his calculations. Soon my chart was on the board. After confirming a few minor details he said that he was quite sure that I was a doctor and started addressing me as such. I am quite sure that we had given him no indication that this might have been so. He had been unaware of our plans to visit him and had no forewarning.

\section{Problems of the heart calculated}

With barely a glance at me to confirm whether this was true, he continued with his calculations and his construction of the chart. The time that my father died was calculated with a fair degree of precision. "Surgical treatment at the age of 13 "-I broke my femur playing rugby - "problems of the heart"- a broken relation- 